Archived version from NCDOCKS Institutional Repository http://libres.uncg.edu/ir/asu/

\title{
Appalachľăn
}

$\overline{\text { B O O N E, NORT H C A R O L I N A }}$

\section{The Effects Of Prenatal Care Utilization On Maternal Health And Health Behaviors}

\author{
By: Ji Yan
}

\begin{abstract}
While many economic studies have explored the role of prenatal care in infant health production, the literature is sporadic on the effects of prenatal care on the mother. This research contributes to this understudied but important area using a unique large dataset of sibling newborns delivered by 0.17 million mothers. We apply within-mother estimators to find robust evidence that poor prenatal care utilization due to late onset of care, low frequency of care visits, or combinations of the two significantly increases the risks of maternal insufficient gestational weight gain, prenatal smoking, premature rupture of membranes, precipitous labor, no breastfeeding, postnatal underweight, and postpartum smoking. The magnitude of the estimates relative to the respective sample means of the outcome variables ranges from 3\% to $33 \%$. The results highlight the importance of receiving timely and sufficient prenatal care in improving maternal health and health behaviors during pregnancy as well as after childbirth.
\end{abstract}

Yan, J. (2017) The Effects of Prenatal Care Utilization on Maternal Health and Health Behaviors. Health Econ., 26: 1001-1018. doi: 10.1002/hec.3380. Publisher version of record available at: https://onlinelibrary.wiley.com/doi/10.1002/ hec. 3380 


\title{
THE EFFECTS OF PRENATAL CARE UTILIZATION ON MATERNAL HEALTH AND HEALTH BEHAVIORS
}

\author{
JI YAN* \\ Department of Economics, Appalachian State University, Boone, NC, USA
}

\begin{abstract}
SUMMARY
While many economic studies have explored the role of prenatal care in infant health production, the literature is sporadic on the effects of prenatal care on the mother. This research contributes to this understudied but important area using a unique large dataset of sibling newborns delivered by 0.17 million mothers. We apply within-mother estimators to find robust evidence that poor prenatal care utilization due to late onset of care, low frequency of care visits, or combinations of the two significantly increases the risks of maternal insufficient gestational weight gain, prenatal smoking, premature rupture of membranes, precipitous labor, no breastfeeding, postnatal underweight, and postpartum smoking. The magnitude of the estimates relative to the respective sample means of the outcome variables ranges from $3 \%$ to $33 \%$. The results highlight the importance of receiving timely and sufficient prenatal care in improving maternal health and health behaviors during pregnancy as well as after childbirth.
\end{abstract}

KEY WORDS: prenatal care; maternal health; gestational weight gain; smoking; breastfeeding

\section{INTRODUCTION}

One important public health objective in Healthy People 2020 is improving the well being and health of mothers in the USA (US Department of Health and Human Services, 2012). Over the last four decades, legislators and policymakers have substantially improved access to affordable coverage and care for American mothers. In particular, mothers have significantly increased prenatal care use through healthcare reform (Blumenthal and Collins, 2014; Currie and Gruber, 1996; Epstein and Newhouse, 1998; US Department of Health and Human Services, 2015). ${ }^{1}$ Contemporary prenatal care allows health professionals to instruct mothers on proper nutritional diet, smoking cessation, illness prevention, and benefits of breastfeeding throughout the course of pregnancy. During regular check-ups, physicians assess changes to mothers' weight and uterus size, as well as monitor and treat various maternal health problems while promoting healthy lifestyles that benefit mothers and infants (American College of Obstetricians and Gynecologists, 2012). Therefore, it is reasonable to expect that by connecting mothers with the healthcare system, prenatal care will

\footnotetext{
*Correspondence to: Department of Economics, Appalachian State University, PO Box 32051, Boone, NC 28608, USA. E-mail: yanj@appstate. edu

${ }^{1}$ The states had greatly expanded Medicaid insurance for low-income pregnant mothers, which increased prenatal care usage. But women on Medicaid could lose coverage between pregnancies. The recent reform by Affordable Care Act overcomes this limitation by providing Medicaid mothers with continuous coverage.
} 
make a difference on maternal health and health behaviors during pregnancy, childbirth, and the postpartum period.

To date, much of the literature on the efficacy of prenatal care has focused on infant outcomes such as birth weight. Recent economic research on newborn birth weight has reported inconsistent results, which vary significantly by research design (e.g., Abrevaya and Dahl, 2008; Conway and Deb, 2005; Evans and Lien, 2005; Reichman et al., 2009). In contrast, very little is known about how mothers benefit from receipt of adequate prenatal care themselves (see Conway and Kutinova (2006) for a review). A few early works look at women in developing countries and provide descriptive evidence that prenatal care reduces maternal morbidity and mortality (Acharya, 1995; McDonagh, 1996). A recent study by Nizalova and Vyshnya (2010) demonstrates that a maternal health program in Ukraine reduces the rates of several pregnancy and delivery complications, by enhancing labor, delivery services, and prenatal care.

To the best of our knowledge, only three economic studies have examined the relation of prenatal care to maternal health in the context of the USA. Conway and Kutinova (2006) show that receiving adequate prenatal care lessens the chances of maternal excessive hospitalization after the newborn delivery and becoming underweight postpartum. Reichman et al. (2010) present evidence about the lasting beneficial effects of early prenatal care initiation on maternal postnatal smoking, well-baby visits, and breastfeeding. However, the findings of the two cross-sectional analyses are suggestive and somewhat sensitive to model specifications, in part because it is hard to sufficiently deal with the unobservable mother heterogeneity correlated with prenatal care utilization. In addition, Kutinova and Conway (2008) report that Medicaid expansions lower the incidences of maternal anemia and pregnancy-induced hypertension, while this effect appears not to operate mainly through improved prenatal care. On the whole, the existing evidence is sparse and inconclusive about the influences of prenatal care on mothers.

Exploring the efficacy of prenatal care in enhancing maternal well being will significantly increase our understanding of maternal health production, which goes beyond the usual framework of newborn health production. The revealed beneficial effects on mothers also add new insights on the cost-benefit analysis of interventions to promote prenatal care. A well-known challenge in this area, however, is the difficulty of measuring maternal health especially the outcomes during pregnancy. It is tempting to consider maternal pregnancy complications, many of which are developed in the mid-pregnancy. Nevertheless, standard health surveys usually focus on detection of such complications in mid-pregnancy (e.g., onset of gestational hypertension studied in prior research) but rarely report successful treatment on any detected health problem in the subsequent visits. Therefore, this incomplete reporting makes prenatal care appear less effective than it actually is in reducing such maternal complications, biasing the impact estimate to zero. Moreover, Conway and Kutinova (2006) point out that it will be promising to study 'subtle' maternal outcomes in new research, which reveals how prenatal care affects women's lifestyle habit during and after pregnancy. One subtle outcome of interest not fully explored before is gestational weight gain, which can be modified by prenatal counseling on diet, nutrition, and exercise. Lastly, prenatal care can affect mother's postnatal outcomes both directly by health education and indirectly by influencing infant health and the associated maternal investment response to child birth endowments. The direct impact can be isolated by controlling newborn birth weight.

This study sheds new light on the role of prenatal care in improving maternal health and health behaviors, using a very large dataset of 0.35 million sibling births linked to 0.17 million mothers. This dataset, constructed from the universe of births in two states, contains rich information on prenatal care and maternal health plus health behaviors across consecutive pregnancies. ${ }^{2}$ As such, it provides a unique opportunity to

\footnotetext{
${ }^{2}$ In both states (Pennsylvania and Washington), low-income women qualify for Medicaid insurance during pregnancy and in the 2 months postpartum. It covers pregnancy-related services and other health care for the mother. Because insurance coverage can affect both prenatal care and maternal outcomes, we control for the types of health insurance (Medicaid, private insurance, etc.) used by mothers in the empirical analysis in the succeeding discussion.
} 
apply empirical models with mother fixed effects to compare various maternal outcomes by the timing of care onset, frequency of care visits, and combinations of the two. This within-family design removes the bias on the estimated effects of prenatal care because of the unobserved mother heterogeneity. The specifications we use also control for many observed characteristics of infants, mothers, and families. Moreover, the large size of our sample yields more precise estimates than previous studies.

In this research, we analyze two sets of adverse and preventable health outcomes of the mother during pregnancy, in a spirit similar to Conway and Kutinova (2006). The first set, closely related to the maternal lifestyle, consists of insufficient gestational weight gain, excessive gestational weight gain, and prenatal smoking. Inappropriate weight gain during pregnancy due to either nutritional deficiency or over-nutrition is an important risk factor for maternal morbidity. ${ }^{3}$ Prenatal smoking significantly increases the incidences of a wide range of maternal complications (Center for Chronic Disease Prevention and Health Promotion, 2001; Roelands et al., 2009). In light of the concern of incomplete reporting on treatment, this study focuses on the total weight gain and smoking beyond the first trimester. The reason is when early onset of care detects inappropriate weight change or smoking but subsequent visits provide successful treatments later in pregnancy, using the two outcomes will capture this effect as part of the 'effectiveness' of timely care initiation. The second set includes premature rupture of membranes (PROM) and onset of precipitous labor. Both reflect severe health conditions near childbirth and can result in significant maternal morbidity. ${ }^{4}$ PROM leads to higher rates of infections and several complications (Cararach et al., 1993; Duff, 1991; Poma, 1996). Precipitous labor, often characterized by intense and painful uterine contractions, is associated with elevated risks of lacerations of the cervix, placental abruption, and uterine rupture (Cunningham et al., 2001; Mahon et al., 1994; Sheiner et al., 2004).

We also investigate the following poor postnatal outcomes: no breastfeeding, unhealthy body weight, and postpartum smoking. Compared with breastfeeding mothers, mothers who do not breastfeed infants are more likely to develop breast cancer, ovarian cancer, and depression and are less protected against infections (Furberg et al., 1999; Ip et al., 2007; Labbok, 2001; Luan et al., 2013). Unhealthy body weight is a serious health threat for women. Previous studies report a U-shape or J-shape association between body mass index (BMI) and many health problems including respiratory disease, cardiovascular disease, physical and mental disorders, and cancers (Ford et al., 2001; Hu, 2003; Kelly et al., 2010). Furthermore, postpartum smoking negatively impacts women's health in many ways (McAfee and Burnette, 2014; Seltzer, 2000). Applying withinmother estimators, we find robust evidence that late care onset and low frequency of visits (or combinations of the two) increase the risks of most of the aforementioned adverse outcomes.

\section{DATA}

The data for this study came from the natality records of all the live births in the states of Pennsylvania (years 2003-2010) and Washington (years 2003-2006). In 2003, both states started adopting the new US Standard Certificates of Live Birth (2003 revision). In addition to utilization of prenatal care, the revised certificate codes rich information on maternal health and health behaviors during pregnancy, childbirth, and the postpartum period. Under access permission to the birth files by the two state departments of public health, consecutive singleton births are linked to the same mother by mother's name, date of birth, race, and newborn parity. The women who had one or more than three births in the sample period or were non-residents of

\footnotetext{
${ }^{3}$ Women with low weight gain and deficient nutrition intake during pregnancy are at elevated risks of hyperemesis, anemia, preterm rupture of membranes, and other complications (Dodds et al., 2006; Gosselink et al., 1992; Villar et al., 2003; Viswanathan et al., 2008). Excessive weight gain is associated with pregnancy-induced hypertension, impaired glucose tolerance, and gestational diabetes (De la Torre et al., 2011; Hedderson et al., 2010; Institute of Medicine, 2009).

${ }^{4}$ Recall the concern on incomplete reporting of subsequent treatments only applies to health problems detected in mid-pregnancy. So it does not affect the results for maternal outcomes at the end of pregnancy.
} 
either state were dropped. ${ }^{5}$ Furthermore, the difference in study period length of the two states suggests that the sampled women in Pennsylvania were more likely to have three or more births than those in Washington while less likely to have only one birth. As a result, the Pennsylvania sibling sample for prenatal outcomes in the succeeding discussion has a greater ratio of the two-birth to three-birth mothers than the one of Washington. This cross-sample asymmetry in mother composition is a limitation of this study when we analyze the pooled two-state sibling data.

With the aforementioned exclusions, two final samples are constructed: one on maternal prenatal health and health behaviors plus breastfeeding, the other on postpartum maternal body weight and smoking. The first sample consists of 147,157 mothers with two births and 19,207 mothers with three births during the study period of both states, totaling 351,935 observations (mother-infant pairs). Because the original birth files do not report postpartum maternal body weight or smoking, we use the panel of the 19,207 three-birth mothers to work out proxy variables. Specifically, maternal weight and smoking 3 months before the current conception are used as proxies for postpartum weight and smoking after the last birth. This method gives postpartum proxy outcomes after the first two births (in the study period) for the three-birth mothers, yielding the second sample of 38,414 observations. ${ }^{6}$

Most maternal health measures such as weight gain, precipitous labor, PROM, and breastfeeding come from medical records completed by hospital staff. Smoking is a self-reporting variable. Because mothers were asked to report the amount of cigarettes smoked by trimester, under-reporting of smoking may be less pronounced at the extensive (participation) margin than the intensive margin. As such, our analysis in the succeeding discussion focuses on smoking at the extensive margin. Furthermore, heavy users of tobacco who smoke throughout pregnancy and use little prenatal care may significantly under-report their smoking participation. In such a case, our estimates will understate the true effect of inadequate prenatal care on smoking and can be seen as lower bounds.

This study uses four sets of measures of poor prenatal care utilization. All of them are expected to increase the risks of the adverse maternal outcomes mentioned previously. The first includes two dummy variables on care initiation (the base is timely onset of care in the first trimester): second-trimester care onset and third-trimester care onset. ${ }^{7}$ Clearly, using the two indicators allows us to compare the mothers with 'late care initiation' to those with 'very late care initiation'. The second one reflects low frequency of care visits. This indicator variable equals 1 (having an insufficient number of visits), if the ratio of a woman's total care visits to the recommended care visits given gestation (American College of Obstetricians and Gynecologists, 2012) is less than 1. The third measure, built upon the Kessner index (Kotelchuck, 1994), assesses care adequacy by integration of the timing of care onset and number of visits. This measure ('inadequate care by the

\footnotetext{
${ }^{5}$ Of all the observations in Pennsylvania, 30\% are mother-infant pairs for the mothers who only had the first baby in $2003-2010$ (i.e., we observe their first birth only; some of the mothers may have additional babies after 2010); $26 \%$ are such pairs for the mothers who had multiple singleton births but only delivered one newborn (the second, third, etc.) in the sample period; $2 \%$ for the mothers whom we observe having more than three births; and the other $42 \%$ (retained in the sample) for the mothers with two or three births in the sample period. (No such statistics for WA. The state Department of Health matched all the two or three sibling births without providing us the raw data.) Compared with the retained two-birth to three-birth mothers in PA, the mothers with only the first birth were more likely to be Black/ Hispanic and unmarried, while mothers with more than three births were less educated and more likely to enroll into Medicaid or WIC. The dropped women with multiple births but only observed once were slightly negatively selected than the retained ones, but the two groups were similar in maternal health and prenatal care utilization. Additional analysis on external validity shows the results from the sample on the mothers with the first and second birth are similar to those from the other sample of all the mothers we observe twice in the study period (such mothers gave birth to two babies with varying birth orders). Future studies need to analyze this issue on the mothers with only one birth.

${ }^{6}$ In this sample, the average time between the last childbirth and 3 months before the current pregnancy is about 15 months. It is close to the period between the last birth and the time point when postpartum outcomes after the last newborn delivery were surveyed in other datasets (Conway and Kutinova, 2006; Reichman et al., 2010). As such, the aforementioned proxy variables are arguably similar to the true postpartum counterparts.

${ }^{7}$ Here, the group of women with third-trimester care onset is broadly defined, which includes a very small number of mothers who reported receiving no care (the extreme case of 'very late onset of care'). Dropping these observations gives very similar results.
} 
Kessner index') is coded as 1 for the women receiving 'inadequate' or 'intermediate' care by the Kessner index, otherwise 0. The last one is based on the Adequacy of Prenatal Care Utilization (APNCU) index (Kotelchuck, 1994). We call this measure 'inadequate care by the APNCU index', and it equals 1 for the women with 'inadequate' or 'intermediate' care by this index (the reference group receives 'adequate' or 'adequate plus' care). ${ }^{8}$ In general, women with both late care initiation and low frequency of visits are rated to almost the same degree as 'having inadequate care' by the last two measures on poor utilization of prenatal care.

The methods by which we construct the maternal outcomes merit further discussion. First, a newly issued guideline by the Institute of Medicine provides the recommended gestational weight gain ranges, which vary by pre-pregnancy BMI category (Institute of Medicine, 2009). By this guideline, we define two types of unhealthy gestational weight gain: 'inadequate' (weight gain below the ranges) and 'excessive' (weight gain above the ranges). Second, because care onset in the first trimester will promote smoking cessation later in pregnancy, we code the women smoking in the second or third trimester as 'prenatal smokers' in the baseline analysis and hypothesize a positive association between late care initiation and this outcome variable. Additional sensitivity analysis considers the women smoking in any trimester as 'prenatal smokers'. ${ }^{9}$ Third, as to maternal postnatal weight, we regroup the standard BMI categories into 'underweight' $\left(<18.5 \mathrm{~kg} / \mathrm{m}^{2}\right)$, 'normal weight' (reference, $18.5-25 \mathrm{~kg} / \mathrm{m}^{2}$ ), and 'overweight or obesity' ( $>25 \mathrm{~kg} / \mathrm{m}^{2}$ ), because both overweight and obesity are considered having more body fat than is optimally healthy. Fourth, we use simple indicator variables on all the other adverse prenatal and postnatal outcomes (PROM, onset of precipitous labor, no breastfeeding, and postpartum smoking).

\section{METHOD}

To assess the relation between prenatal care and maternal prenatal health plus health behaviors, we apply the following baseline specification:

$$
Y_{i j}=\alpha_{0}+\alpha_{1} \text { Prenatal } \text { Care }_{i j}+\alpha_{2} X_{i j}+\alpha_{3} W_{i j}+\mu_{i}+\varepsilon_{i j}
$$

where $Y_{i j}$ is one of the five adverse prenatal outcomes for mother $i$ with infant $j$ and Prenatal Care is one of the measures of poor utilization of prenatal care noted earlier for the same mother and infant. $X$ is a rich set of birthvariant characteristics of the mother (age, education, marital status, WIC enrollment, infant delivery payment types (Medicaid, private insurance, etc.), and year and month indicators), ${ }^{10}$ the father (age, education, race, and ethnicity), and the infant (gender and birth order). $W$ is a vector of the mother's health and behavior prior to pregnancy (pre-pregnancy BMI and smoking). And $\mu_{i}$ is the fixed effect of mother $i$, which captures the unobserved characteristics of the mother and her family across pregnancies. Because this unobserved

\footnotetext{
${ }^{8}$ Compared with the Kessner index, the APNCU index is less weighted toward care initiation (e.g., the cutoff for timely onset of care is the fourth month instead of the third month during pregnancy) while placing a higher standard on the expected visits in defining adequate prenatal care.

${ }^{9}$ Early care onset is supposed to promote smoking cessation right after care initiation (even during the first trimester). To precisely examine this effect, ideally, we should classify the women who quit smoking within the first trimester right after the care onset as nonsmokers ('type 1 quitters' with smoking cessation due to prenatal care) and the women who ceased smoking before the care onset within the first trimester as smokers ('type 2 quitters' who ceased smoking without prenatal care). Unfortunately, we are unable to distinguish the two types of quitters who stopped smoking in the first trimester, because the exact time of smoking cessation was not reported. In this sense, neither measure of 'prenatal smokers' is perfect. The first one (smoking beyond the first trimester) correctly codes the 'type 1 quitters' as nonsmokers but miscodes the 'type 2 quitters' as nonsmokers. In contrast, the second one (smoking in any trimester) miscodes the 'type 1 quitters' as smokers yet correctly codes the 'type 2 quitters' as smokers.

${ }^{10}$ Maternal race and ethnicity are birth invariant and not used in models with mother fixed effects. Still, we report their statistics for the descriptive analysis in the succeeding discussion. In addition, the time dummies vary by the maternal dependent variable: for the prenatal outcomes, we use the year and month of conception, while for the postnatal outcomes, we apply indicators of the year and month when such outcomes were measured.
} 
heterogeneity is very likely to correlate with both prenatal care utilization and maternal outcomes, it is important to control for $\mu_{i}$ to yield unbiased estimates of $\alpha_{1}$ (the effects of prenatal care). Because having bad health outcomes in the last pregnancy can lead women to change body weight or quit smoking before the current conception, this 'feedback' effect suggests pre-pregnancy BMI and smoking (the vector $W$ ) in equation (1) may not be strictly exogenous. Nevertheless, this will not bias the results on the key parameter $\alpha_{1}$, if strict exogeneity holds for prenatal care (Wooldridge, 2002). ${ }^{11}$

When studying the postnatal outcomes, we begin with equation (1) and then consider several variants of this specification. First, the postpartum outcomes examined in this study also capture some features of maternal investment in infants. It opens a potential way connecting prenatal care to postnatal health and health behaviors: through modifying the effects of prenatal shocks on infants, prenatal care may influence mother's investment (e.g., breastfeeding and smoking) in response to newborn health endowment (Almond and Mazumder, 2013; Currie and Almond, 2011). This indirect mechanism, while interesting, does not reflect the direct lasting effect of prenatal care on mother's own postnatal health (via prenatal health education or intervention). If the main interest lies in the direct effect, we can isolate it by controlling infant birth weight $(B W)$ :

$$
\text { Postnatal Outcome } e_{i j}=\alpha_{0}+\alpha_{1} \text { Prenatal Care }_{i j}+\alpha_{2} X_{i j}+\alpha_{3} W_{i j}+\alpha_{4} B W_{i j}+\mu_{i}+\varepsilon_{i j}
$$

where the dependent variable is no breastfeeding, postnatal unhealthy body weight, or postpartum smoking. In the succeeding discussion, we also try adding other birth outcomes in this specification.

Second, recall in sample construction, we use maternal weight and smoking before the current pregnancy as the proxies for postpartum weight and smoking after the last childbirth. So when the dependent variable is specifically postpartum weight or smoking in equation (1) or (2), one element in the $W$ vector is essentially a lagged dependent variable and not strictly exogenous. ${ }^{12}$ In particular, as we apply equation (2), a similar 'feedback effect' story suggests neither the other elements in $W$ nor newborn birth weight is strictly exogenous. Although this implies biased coefficient estimates on $W\left(\hat{\alpha}_{3}\right)$ and $B W\left(\hat{\alpha}_{4}\right)$, again it will not bias the key coefficient estimate on prenatal care. As a further robustness check, we remove such unimportant biases to see if the results are different. Specifically, we difference the fixed effects $\mu_{i}$ in equation (2), assume $W$ and $B W$ sequentially exogenous, and use their lagged values as instruments for $\Delta W$ and $\Delta B W$ (Cameron and Trivedi, 2005; Wooldridge, 2002).

\section{RESULTS}

Table I displays the descriptive statistics of the maternal prenatal outcomes plus breastfeeding, the prenatal care measures, and the maternal and infant characteristics. Column 1 shows that $22 \%$ of the mothers of all the newborns had insufficient gestational weight gain and 50\% of them gained excessive weight. It is worth mentioning that Park et al. (2011) and Truong et al. (2015) also find high rates of excessive gestational weight gain (51.2-52.5\%). Moreover, 14\% of the mothers smoked during pregnancy, and $28 \%$ of them did not breastfeed their babies. In contrast, both PROM and precipitous labor are less prevalent among the pregnant women. As to prenatal care utilization, while about $30 \%$ of the mothers initiated care beyond the first trimester, $62 \%$ had low frequency of visits, and about $30-40 \%$ of them had inadequate care by the APNCU/Kessner index. ${ }^{13}$ The other columns break down the sample by trimester of care onset. Compared with early onset (column 2), care initiation beyond the first trimester exhibits a positive relationship

\footnotetext{
${ }^{11}$ Indeed, in the succeeding discussion, we find none of the adverse prenatal outcomes during the last pregnancy significantly affect prenatal care utilization in the current pregnancy.

${ }^{12}$ As noted earlier, here, we examine two types of postnatal unhealthy body weight ('underweight' and 'overweight or obesity'). So the W vector accordingly consists of two pre-pregnancy body weight indicators plus one indicator of pre-pregnancy smoking.

${ }^{13}$ Alexander and Kotelchuck $(1996,2001)$ report high rates of low frequency of prenatal visits as well.
} 
Table I. Descriptive statistics: adverse maternal health outcomes and health behaviors in pregnancy or right after childbirth

\begin{tabular}{|c|c|c|c|c|c|c|c|c|}
\hline & \multicolumn{2}{|c|}{ (1) } & \multicolumn{2}{|c|}{ (2) } & \multicolumn{2}{|c|}{ (3) } & \multicolumn{2}{|c|}{ (4) } \\
\hline & \multicolumn{2}{|c|}{$\begin{array}{l}\text { Full sample (no. of } \\
\text { mothers }=166,364 \text { ) }\end{array}$} & \multicolumn{2}{|c|}{$\begin{array}{l}\text { Care onset in the } \\
\text { first trimester }\end{array}$} & \multicolumn{2}{|c|}{$\begin{array}{l}\text { Care onset in the } \\
\text { second trimester }\end{array}$} & \multicolumn{2}{|c|}{$\begin{array}{l}\text { Care onset in the } \\
\text { third trimester }\end{array}$} \\
\hline & Mean & SD & Mean & SD & Mean & SD & Mean & SD \\
\hline Insufficient weight gain & 0.22 & $(0.41)$ & 0.21 & $(0.40)$ & 0.25 & $(0.43)$ & 0.29 & $(0.46)$ \\
\hline Excessive weight gain & 0.50 & $(0.50)$ & 0.51 & $(0.50)$ & 0.48 & $(0.50)$ & 0.46 & $(0.50)$ \\
\hline Prenatal smoking & 0.14 & $(0.35)$ & 0.12 & $(0.32)$ & 0.19 & $(0.39)$ & 0.25 & $(0.43)$ \\
\hline Premature rupture of membranes & 0.03 & $(0.18)$ & 0.03 & $(0.17)$ & 0.04 & $(0.19)$ & 0.04 & $(0.19)$ \\
\hline Precipitous labor & 0.04 & $(0.19)$ & 0.03 & $(0.18)$ & 0.05 & $(0.21)$ & 0.06 & $(0.23)$ \\
\hline No breastfeeding & 0.28 & $(0.45)$ & 0.26 & $(0.44)$ & 0.34 & $(0.47)$ & 0.42 & $(0.49)$ \\
\hline Care onset in the second trimester & 0.22 & $(0.42)$ & 0.00 & $(0.00)$ & 1.00 & $(0.00)$ & 0.00 & $(0.00)$ \\
\hline Care onset in the third trimester & 0.06 & $(0.23)$ & 0.00 & $(0.00)$ & 0.00 & $(0.00)$ & 1.00 & $(0.00)$ \\
\hline Low frequency of care visits & 0.62 & $(0.49)$ & 0.53 & $(0.50)$ & 0.79 & $(0.40)$ & 0.96 & $(0.20)$ \\
\hline Inadequate care by the APNCU index & 0.33 & $(0.47)$ & 0.21 & $(0.41)$ & 0.55 & $(0.50)$ & 1.00 & $(0.00)$ \\
\hline Inadequate care by the Kessner Index & 0.41 & $(0.49)$ & 0.18 & $(0.39)$ & 1.00 & $(0.00)$ & 1.00 & $(0.00)$ \\
\hline Mother's age & 27.61 & $(5.59)$ & 28.20 & $(5.38)$ & 26.19 & $(5.82)$ & 25.51 & $(5.80)$ \\
\hline Mother non-Hispanic White & 0.83 & $(0.38)$ & 0.86 & $(0.35)$ & 0.75 & $(0.43)$ & 0.68 & $(0.47)$ \\
\hline Mother non-Hispanic Black & 0.08 & $(0.27)$ & 0.05 & $(0.22)$ & 0.13 & $(0.34)$ & 0.20 & $(0.40)$ \\
\hline Mother Hispanic & 0.06 & $(0.24)$ & 0.05 & $(0.22)$ & 0.08 & $(0.28)$ & 0.09 & $(0.28)$ \\
\hline Mother Asian & 0.03 & $(0.16)$ & 0.03 & $(0.16)$ & 0.03 & $(0.16)$ & 0.02 & $(0.15)$ \\
\hline Mother education $=12$ years & 0.25 & $(0.43)$ & 0.23 & $(0.42)$ & 0.31 & $(0.46)$ & 0.32 & $(0.47)$ \\
\hline Mother education $=13-15$ years & 0.26 & $(0.44)$ & 0.28 & $(0.45)$ & 0.24 & $(0.42)$ & 0.21 & $(0.41)$ \\
\hline Mother education $\geq 16$ years & 0.34 & $(0.47)$ & 0.40 & $(0.49)$ & 0.19 & $(0.39)$ & 0.13 & $(0.33)$ \\
\hline Mother married & 0.70 & $(0.46)$ & 0.76 & $(0.42)$ & 0.56 & $(0.50)$ & 0.46 & $(0.50)$ \\
\hline Mother in WIC & 0.33 & $(0.47)$ & 0.29 & $(0.45)$ & 0.44 & $(0.50)$ & 0.42 & $(0.49)$ \\
\hline Mother on Medicaid & 0.26 & $(0.44)$ & 0.22 & $(0.41)$ & 0.38 & $(0.49)$ & 0.44 & $(0.50)$ \\
\hline Maternal pre-pregnancy obese & 0.19 & $(0.39)$ & 0.19 & $(0.39)$ & 0.19 & $(0.40)$ & 0.20 & $(0.40)$ \\
\hline Maternal pre-pregnancy overweight & 0.23 & $(0.42)$ & 0.23 & $(0.42)$ & 0.23 & $(0.42)$ & 0.24 & $(0.43)$ \\
\hline Maternal pre-pregnancy underweight & 0.05 & $(0.21)$ & 0.04 & $(0.21)$ & 0.06 & $(0.23)$ & 0.06 & $(0.24)$ \\
\hline Maternal smoking before pregnancy & 0.21 & $(0.41)$ & 0.19 & $(0.39)$ & 0.25 & $(0.43)$ & 0.30 & $(0.46)$ \\
\hline Infant male & 0.51 & $(0.50)$ & 0.51 & $(0.50)$ & 0.52 & $(0.50)$ & 0.51 & $(0.50)$ \\
\hline Infant birth order & 2.14 & $(1.22)$ & 2.03 & $(1.05)$ & 2.35 & $(1.45)$ & 2.66 & $(1.79)$ \\
\hline Number of sibling births & 351,935 & & 254,314 & & 78,191 & & 19,430 & \\
\hline
\end{tabular}

The full sample, constructed from natality birth records, consists of all the mothers with two or three live births in the state of Pennsylvania in 2003-2010 and in the state of Washington in 2003-2006. Additional birth variant control variables (not shown) include father's age, race, ethnicity, and education.

SD, standard deviation; APNCU, Adequacy of Prenatal Care Utilization.

with low frequency of care visits, inadequate care by either index, insufficient weight gain, prenatal smoking, and risks of PROM and precipitous labor plus no breastfeeding (columns 3 and 4). Women with late care onset were younger, less educated, and more likely to be Black/Hispanic, unmarried, and enroll in WIC/Medicaid than those with early onset.

Table AI (in the Supporting Information) reports the summary statistics of the smaller sample on postpartum body weight and smoking. After childbirth, about $4 \%$ of the mothers were underweight; $45 \%$ of them were overweight or obese; and about one-fifth smoked cigarettes. The mothers with care initiation beyond the first trimester were more likely to be underweight or smoke after giving birth. Like Table I, late care onset is positively correlated with low frequency of care visits and low socioeconomic status of the mother. Further subsample analysis (not shown) indicates that sufficiency on the number of care visits also appears to make a difference in the maternal prenatal and postnatal health outcomes.

Table II represents the baseline estimates on the effects of prenatal care on the five prenatal outcomes by specification (1). Column 1 shows that second-trimester and third-trimester care onset increase the risk of insufficient gestational weight gain by 0.8 and 2.8 percentage points (on the base of 0.22 ), respectively. The results on low frequency of visits and inadequate care by either index suggest an increase of 0.9-2.2 percentage points on insufficient weight gain (panels 2-4, column 1). In contrast, the association between prenatal care and excessive 
Table II. Effects of prenatal care on prenatal health and health behaviors

\begin{tabular}{|c|c|c|c|c|c|}
\hline & (1) & $(2)$ & (3) & (4) & $(5)$ \\
\hline & $\begin{array}{l}\text { Insufficient } \\
\text { weight gain }\end{array}$ & $\begin{array}{l}\text { Excessive } \\
\text { weight gain }\end{array}$ & $\begin{array}{l}\text { Prenatal } \\
\text { Smoking }\end{array}$ & PROM & Precipitous labor \\
\hline \multicolumn{6}{|l|}{ Panel 1: care onset } \\
\hline Care onset in the second trimester & $\begin{array}{l}0.008 * * * \\
(0.002)\end{array}$ & $\begin{array}{c}0.002 \\
(0.003)\end{array}$ & $\begin{array}{l}0.006^{* * * *} \\
(0.001)\end{array}$ & $\begin{array}{l}0.004 * * * \\
(0.001)\end{array}$ & $\begin{array}{l}0.005^{* * *} \\
(0.001)\end{array}$ \\
\hline Care onset in the third trimester & $\begin{array}{l}0.028 * * * \\
(0.004)\end{array}$ & $\begin{array}{c}-0.004 \\
(0.005)\end{array}$ & $\begin{array}{l}0.014 * * * \\
(0.002)\end{array}$ & $\begin{array}{l}0.008 * * * \\
(0.002)\end{array}$ & $\begin{array}{l}0.010^{* * *} \\
(0.002)\end{array}$ \\
\hline \multicolumn{6}{|l|}{ Panel 2: number of visits } \\
\hline Low frequency of care visits & $\begin{array}{l}0.009 * * * \\
(0.002)\end{array}$ & $\begin{array}{c}0.001 \\
(0.002)\end{array}$ & $\begin{array}{l}0.009^{* * * *} \\
(0.001)\end{array}$ & $\begin{array}{l}0.003^{* * * *} \\
(0.001)\end{array}$ & $\begin{array}{l}0.006 * * * \\
(0.001)\end{array}$ \\
\hline \multicolumn{6}{|l|}{ Panel 3: care adequacy 1} \\
\hline Inadequate care (by the APNCU index) & $\begin{array}{l}0.022 * * * \\
(0.002)\end{array}$ & $\begin{array}{c}0.001 \\
(0.002)\end{array}$ & $\begin{array}{l}0.010^{* * * *} \\
(0.001)\end{array}$ & $\begin{array}{l}0.003^{* * * *} \\
(0.001)\end{array}$ & $\begin{array}{l}0.005 * * * \\
(0.001)\end{array}$ \\
\hline \multicolumn{6}{|l|}{ Panel 4: care adequacy 2} \\
\hline Inadequate care (by the Kessner index) & $\begin{array}{l}0.019 * * * \\
(0.002)\end{array}$ & $\begin{array}{c}-0.002 \\
(0.002)\end{array}$ & $\begin{array}{l}0.009 * * * \\
(0.001)\end{array}$ & $\begin{array}{l}0.008 * * * \\
(0.001)\end{array}$ & $\begin{array}{l}0.004 * * * \\
(0.001)\end{array}$ \\
\hline Maternal and paternal controls & $\mathrm{Y}$ & Y & $\mathrm{Y}$ & Y & $\mathrm{Y}$ \\
\hline Infant gender and birth order & $\mathrm{Y}$ & $\mathrm{Y}$ & $\mathrm{Y}$ & $\mathrm{Y}$ & $\mathrm{Y}$ \\
\hline Mother fixed effects & Y & $\mathrm{Y}$ & Y & Y & Y \\
\hline Sample mean (prenatal outcomes) & 0.22 & 0.50 & 0.14 & 0.03 & 0.04 \\
\hline Number of mothers & 166,364 & 166,364 & 166,364 & 166,364 & 166,364 \\
\hline Number of sibling births & 351,935 & 351,935 & 351,935 & 351,935 & 351,935 \\
\hline
\end{tabular}

All the regressions use the full sample of mothers with two or three births. The maternal control variables include mother's age, education, marital status, WIC enrollment, delivery payment types, pre-pregnancy BMI and smoking, and year and month of conception; the paternal control variables are father's age, race, ethnicity, and education. Robust standard errors clustered at the mother's level are reported in parentheses. PROM, premature rupture of membranes; APNCU, Adequacy of Prenatal Care Utilization; BMI, body mass index.

*Significant at $10 \%$ level;

**significant at $5 \%$ level;

$* * *$ significant at $1 \%$ level.

weight gain is weak and insignificant (column 2). ${ }^{14}$ Column 3 demonstrates that the women who initiate care beyond the first trimester are more likely to smoke in the second or third trimester by 0.6-1.4 percentage points, a 4-10\% increase. Again, the effects are stronger for the women who delay obtaining care until the third trimester or have no care. Likewise, late onset of prenatal care significantly increases the risks of PROM and precipitous labor by $13-27 \%$ of the sample means (columns 4 and 5). With respect to the other prenatal care measures, panels 2 to 4 show low frequency of visits and inadequate care are associated with a 6-27\% increase in the incidences of prenatal smoking, PROM, and precipitous labor. We have also alternatively defined the women smoking in any trimester as prenatal smokers, with the results (suppressed) close to column 3 across all the prenatal care measures.

Table III explores two subsamples by number of sibling births. For both the two-birth mothers and three-birth mothers, poor prenatal care utilization is significantly associated with higher risks of insufficient weight gain, prenatal smoking, PROM, and precipitous labor, regardless of which care measure we use. Table IV reports the estimates by state. They are also consistent with the baseline results in Table II. Furthermore, the estimated impacts of poor prenatal care utilization on the four prenatal outcomes (relative to the respective sample means) are larger for the women in the state of Washington than Pennsylvania. The heterogeneous effects may be partly attributable to the cross-state difference in the quality of prenatal care. ${ }^{15}$ For instance, according to the statistics of the Pregnancy

\footnotetext{
${ }^{14}$ This finding is line with a recent study by Yeo et al. (2016). But their study neither controls for mother unobserved heterogeneity nor examines any maternal outcome other than weight gain. As one possible explanation for the weak effect, the beneficial influence of adequate prenatal care on weight gain control (through nutritional counseling) may be canceled out by its impact on prenatal smoking because smoking cessation leads to weight gain (Cawley et al., 2004). We test this by restricting the sample to the non-smoking women and find the effect estimates of late care onset, and low frequency of care visits become larger but still insignificant. Additional analysis provides suggestive evidence that adequate prenatal care slightly reduces excessive weight gain for the obese and overweight women (a high-risk population for excessive weight gain).

${ }^{15} \mathrm{We}$ do not find evidence that such heterogeneous effects are driven by the asymmetric composition of two-birth and three-birth mothers cross the two state subsamples.
} 


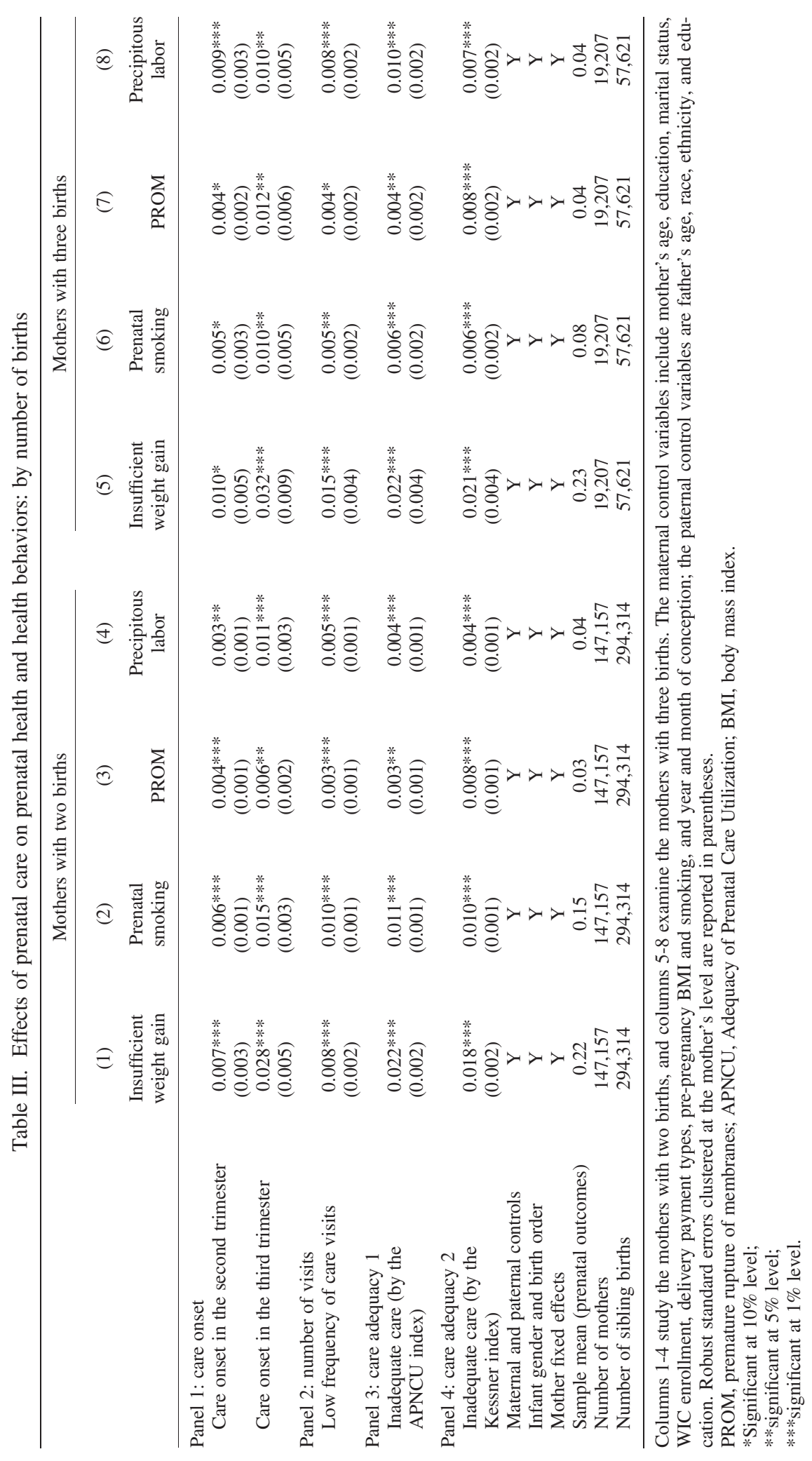


Table IV. Effects of prenatal care on prenatal health and health behavior: by state

\begin{tabular}{|c|c|c|c|c|c|c|c|c|}
\hline & \multicolumn{4}{|c|}{ Mothers in PA } & \multicolumn{4}{|c|}{ Mothers in WA } \\
\hline & (1) & (2) & (3) & (4) & (5) & (6) & (7) & (8) \\
\hline & $\begin{array}{l}\text { Insufficient } \\
\text { weight gain }\end{array}$ & $\begin{array}{l}\text { Prenatal } \\
\text { smoking }\end{array}$ & PROM & $\begin{array}{l}\text { Precipitous } \\
\text { labor }\end{array}$ & $\begin{array}{l}\text { Insufficient } \\
\text { weight gain }\end{array}$ & $\begin{array}{l}\text { Prenatal } \\
\text { smoking }\end{array}$ & PROM & $\begin{array}{l}\text { Precipitous } \\
\text { labor }\end{array}$ \\
\hline \multicolumn{9}{|l|}{ Panel 1: care onset } \\
\hline $\begin{array}{l}\text { Care onset in the } \\
\text { second trimester }\end{array}$ & $\begin{array}{l}0.006 * * \\
(0.002)\end{array}$ & $\begin{array}{l}0.006 * * * \\
(0.001)\end{array}$ & $\begin{array}{l}0.003 * * * \\
(0.001)\end{array}$ & $\begin{array}{l}0.004 * * * \\
(0.001)\end{array}$ & $\begin{array}{l}0.025 * * * \\
(0.007)\end{array}$ & $\begin{array}{l}0.008 * * * \\
(0.003)\end{array}$ & $0.011 * * *$ & $0.012 * * *$ \\
\hline $\begin{array}{l}\text { Care onset in the } \\
\text { third trimester }\end{array}$ & $\begin{array}{l}0.024 * * * \\
(0.005)\end{array}$ & $\begin{array}{l}0.014 * * * \\
(0.003)\end{array}$ & $\begin{array}{l}0.009 * * * \\
(0.002)\end{array}$ & $\begin{array}{l}0.009 * * * \\
(0.002)\end{array}$ & $\begin{array}{l}0.063 * * * \\
(0.015)\end{array}$ & $\begin{array}{l}0.017 * * * \\
(0.006)\end{array}$ & $\begin{array}{c}0.014^{*} \\
(0.008)\end{array}$ & $\begin{array}{l}0.015^{* *} \\
(0.008)\end{array}$ \\
\hline \multicolumn{9}{|c|}{ Panel 2: number of visits } \\
\hline $\begin{array}{l}\text { Low frequency } \\
\text { of care visits }\end{array}$ & $\begin{array}{l}0.009 * * * \\
(0.002)\end{array}$ & $\begin{array}{l}0.009 * * * \\
(0.001)\end{array}$ & $\begin{array}{l}0.002 * * \\
(0.001)\end{array}$ & $\begin{array}{l}0.006 * * * \\
(0.001)\end{array}$ & $\begin{array}{l}0.010^{*} \\
(0.005)\end{array}$ & $\begin{array}{l}0.007 * * * \\
(0.002)\end{array}$ & $\begin{array}{c}0.005^{*} \\
(0.003)\end{array}$ & $\begin{array}{l}0.007 * * * \\
(0.003)\end{array}$ \\
\hline \multicolumn{9}{|c|}{ Panel 3: care adequacy 1} \\
\hline $\begin{array}{l}\text { Inadequate care } \\
\text { (by the APNCU } \\
\text { index) }\end{array}$ & $\begin{array}{l}0.020 * * * \\
(0.002)\end{array}$ & $\begin{array}{l}0.011 * * * \\
(0.001)\end{array}$ & $\begin{array}{l}0.002 * * \\
(0.001)\end{array}$ & $\begin{array}{l}0.005^{* * * *} \\
(0.001)\end{array}$ & $\begin{array}{l}0.032 * * * \\
(0.005)\end{array}$ & $\begin{array}{l}0.007 * * * \\
(0.002)\end{array}$ & $\begin{array}{l}0.007 * * \\
(0.003)\end{array}$ & $\begin{array}{l}0.007 * * \\
(0.003)\end{array}$ \\
\hline \multicolumn{9}{|c|}{ Panel 4: care adequacy 2} \\
\hline $\begin{array}{l}\text { Inadequate care (by } \\
\text { the Kessner index) }\end{array}$ & $\begin{array}{l}0.017 * * * \\
(0.002)\end{array}$ & $\begin{array}{l}0.010 * * * \\
(0.001)\end{array}$ & $\begin{array}{l}0.007 * * * \\
(0.001)\end{array}$ & $\begin{array}{l}0.003 * * * \\
(0.001)\end{array}$ & $\begin{array}{l}0.032 * * * \\
(0.006)\end{array}$ & $\begin{array}{l}0.007 * * * \\
(0.002)\end{array}$ & $\begin{array}{l}0.012 * * * \\
(0.003)\end{array}$ & $\begin{array}{l}0.008 * * * \\
(0.003)\end{array}$ \\
\hline $\begin{array}{l}\text { Maternal and } \\
\text { paternal controls }\end{array}$ & $\mathrm{Y}$ & $\mathrm{Y}$ & $\mathrm{Y}$ & $\mathrm{Y}$ & $\mathrm{Y}$ & $\mathrm{Y}$ & $\mathrm{Y}$ & $\mathrm{Y}$ \\
\hline $\begin{array}{l}\text { Infant gender } \\
\text { and birth order }\end{array}$ & $\mathrm{Y}$ & $\mathrm{Y}$ & $\mathrm{Y}$ & $\mathrm{Y}$ & $\mathrm{Y}$ & $\mathrm{Y}$ & $\mathrm{Y}$ & $\mathrm{Y}$ \\
\hline $\begin{array}{l}\text { Mother fixed } \\
\text { effects }\end{array}$ & $\mathrm{Y}$ & $\mathrm{Y}$ & $\mathrm{Y}$ & $\mathrm{Y}$ & $\mathrm{Y}$ & $\mathrm{Y}$ & $\mathrm{Y}$ & $\mathrm{Y}$ \\
\hline $\begin{array}{l}\text { Sample mean } \\
\text { (prenatal } \\
\text { outcomes) }\end{array}$ & 0.22 & 0.15 & 0.03 & 0.04 & 0.23 & 0.08 & 0.04 & 0.04 \\
\hline $\begin{array}{l}\text { Number of } \\
\text { mothers }\end{array}$ & 141,426 & 141,426 & 141,426 & 141,426 & 24,938 & 24,938 & 24,938 & 24,938 \\
\hline $\begin{array}{l}\text { Number of } \\
\text { sibling births }\end{array}$ & 301,234 & 301,234 & 301,234 & 301,234 & 50,701 & 50,701 & 50,701 & 50,701 \\
\hline
\end{tabular}

Columns 1-4 focus on the mothers in the state of Pennsylvania, and columns 5-8 examine the mothers in the state of Washington. The maternal control variables include mother's age, education, marital status, WIC enrollment, delivery payment types, pre-pregnancy BMI and smoking, and year and month of conception; the paternal control variables are father's age, race, ethnicity, and education. Robust standard errors clustered at the mother's level are reported in parentheses.

PA, Pennsylvania; WA, Washington; PROM, premature rupture of membranes; APNCU, Adequacy of Prenatal Care Utilization; BMI, body mass index.

*Significant at $10 \%$ level;

**significant at $5 \%$ level;

****significant at $1 \%$ level.

Risk Assessment Monitoring System, pregnant women in Washington received better counseling on various health behaviors (breastfeeding, drug use, etc.) in prenatal care visits than those in Pennsylvania in year 2010. Nevertheless, early onset (or having a high frequency) of relatively 'high-quality' care (Washington) is very likely to have a stronger beneficial health effect for the mother than receiving timely or sufficient 'low-quality' care (Pennsylvania). Additional subsample analysis as discussed earlier reveals a weak and insignificant relation between prenatal care and excessive weight gain (not shown). Overall, the robust findings on gestational weight gain suggest that receipt of timely and sufficient prenatal care is more effective in reducing deficient nutrient intake than curbing over-nutrition during pregnancy.

One methodological concern is that, because birth-varying variables (shocks) not controlled in the baseline analysis may affect both prenatal care and maternal outcomes, they can bias the within-mother estimates. Such factors include stress, income, employment, and family relationship. Although the dataset does not include maternal stress information, we can mitigate the potential bias by controlling for maternal hypertension and the county level unemployment rate. The former (hypertension) captures an important pathway for stress to 
impact mother's health (Boone, 1991). The latter is a key stressor during pregnancy (see Carlson (2015) for a review), which can affect both maternal health through inducing distress and prenatal care via a substitution effect between non-market and market activities plus an income effect from changes in employment. Moreover, we do not have information on family income because of data limitations. However, the supplementary files for the Washington birth data do code maternal employment status and labor force participation (no such files available for Pennsylvania). It allows us to additionally control for individual-level changes in employment status across pregnancies. As to family structure, we have included an indicator of being married in the baseline analysis. Additional family relationships such as remarriage and cohabitation merit consideration in future research.

Table V shows the sensitivity analysis discussed previously for prenatal outcomes. Columns 1-4 indicate that the previous estimates from the Pennsylvania subsample in Table IV are nearly unchanged, when we control pre-pregnancy and gestational hypertensions, county level unemployment rate, and year by month effects. The results (not shown) are also robust in a smaller sample of years 2003-2006 when the Pennsylvania mothers were not exposed to the 2008 financial crisis (a large-scale stressful event). Columns 5-8 further add indictors of maternal unemployment and out-of-labor force to analyze the Washington subsample. The new estimates are very similar to the counterparts in Table IV. Lastly, additional exercises using the full sample or either one of the two hypertension controls again produce robust evidence.

Table VI reports the association between prenatal care and postnatal breastfeeding. Column 1 indicates that care onset beyond the first trimester increases the risk of no breastfeeding by $0.8-3.1$ percentage points $(3-11 \%)$. The women with low frequency of care and inadequate care by either index are also 1.1-1.9 percentage points less likely to breastfeed the newborn. Column 2 adds newborn birth weight to control for responsive investments by specification (2), with the results close to column 1 . The new estimates on care initiation and inadequacy (by the Kessner index) are slightly smaller. The findings are similar, when we include alternative birth outcomes such as low birth weight and preterm birth (not shown for brevity). Overall, the isolated direct effect of prenatal care (e.g., through prenatal health education) is the main driving force of the estimated total effect in column 1. The other columns illustrate the results by state and by number of birth. All of them are consistent with the case using the full sample. Furthermore, the effects of poor prenatal care are again stronger for the Washington women.

Table VII investigates the other postnatal maternal outcomes. Column 1 shows both late initiation of prenatal care and low frequency of care visits raise the likelihood of postnatal underweight by about 1-1.3 percentage points (25-33\% on the base of 0.04). Similar results hold for the two measures on care inadequacy. We also find suggestive evidence that the women who were underweight before pregnancy but received inadequate prenatal care are less likely to maintain a healthy weight postpartum and the normal weight women with inadequate care are at an elevated risk of becoming underweight after childbirth. Column 3 displays small and insignificant effects of prenatal care on postnatal overweight or obesity. ${ }^{16}$ Column 5 suggests that poor prenatal care utilization because of late onset or low frequency of visits (or combinations of the two) increases the risk of maternal smoking postpartum by about $4-10 \%$. Controlling for newborn birth weight in the even-numbered columns yields very similar results, suggesting again the primary contributor to the baseline estimates is the direct effect of prenatal care on women's own health. The results for all the four postnatal outcomes are robust in

\footnotetext{
${ }^{16}$ One concern is that the postnatal weight measures used here are not good representations of the true postpartum body weight of all the women after newborn delivery, because the women who planned another pregnancy may be slower to lose weight than those who did not plan another child in the sample period. Clearly, the latter can be divided into two groups: the women who did not conceive another baby as planned and those who did not plan another child but had an unintended pregnancy. Although our sample does not contain observations of the first group, we can roughly identify many young women in the second group. By Fertig and Watson (2009), birth certificates with missing information on paternal age are very likely to be the results of unintended pregnancies. We then contrast the women below age 25 years without paternal age coded (unintended pregnancy) and those with paternal age on postnatal BMI, underweight, and overweight or obesity. Interestingly, the means of all the weight measures are similar and not statistically different across the two types of mothers. We leave further analysis on this issue for future work.
} 


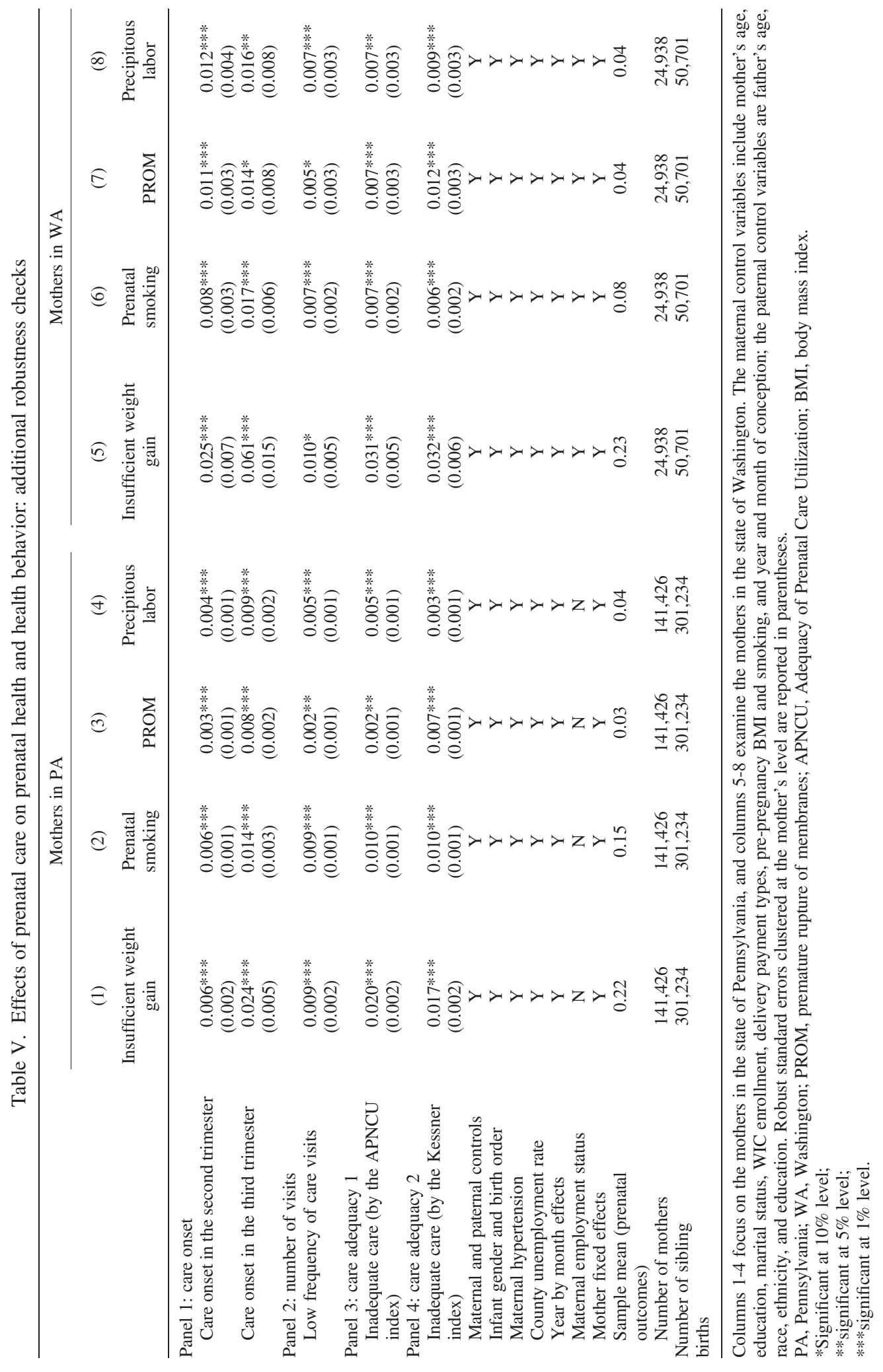


Table VI. Effects of prenatal care on breastfeeding

\begin{tabular}{|c|c|c|c|c|c|c|}
\hline & \multicolumn{6}{|c|}{ Dependent variable: no breastfeeding } \\
\hline & (1) & (2) & (3) & (4) & (5) & (6) \\
\hline & $\begin{array}{c}\text { Full } \\
\text { sample }\end{array}$ & $\begin{array}{c}\text { Full } \\
\text { sample }\end{array}$ & $\begin{array}{l}\text { Mothers in } \\
\text { PA }\end{array}$ & $\begin{array}{l}\text { Mothers in } \\
\text { WA }\end{array}$ & $\begin{array}{l}\text { Mothers with two } \\
\text { births }\end{array}$ & $\begin{array}{l}\text { Mothers with three } \\
\text { births }\end{array}$ \\
\hline \multicolumn{7}{|l|}{ Panel 1: care onset } \\
\hline Care onset in the second & $0.008 * * *$ & $0.007 * * *$ & $0.006 * * *$ & $0.017 * * *$ & $0.008 * * *$ & $0.008^{*}$ \\
\hline trimester & $(0.002)$ & $(0.002)$ & $(0.002)$ & $(0.005)$ & $(0.002)$ & $(0.004)$ \\
\hline Care onset in the third & $0.031 * * *$ & $0.030 * * *$ & $0.029 * * *$ & $0.041 * * *$ & $0.032 * * *$ & $0.026^{* * * *}$ \\
\hline trimester & $(0.004)$ & $(0.004)$ & $(0.004)$ & $(0.011)$ & $(0.005)$ & $(0.008)$ \\
\hline \multicolumn{7}{|l|}{ Panel 2: number of visits } \\
\hline Low frequency of care visits & $\begin{array}{l}0.011 * * * \\
(0.002)\end{array}$ & $\begin{array}{l}0.011 * * * \\
(0.002)\end{array}$ & $\begin{array}{l}0.010^{* * * *} \\
(0.002)\end{array}$ & $\begin{array}{l}0.018 * * * \\
(0.004)\end{array}$ & $\begin{array}{l}0.011 * * * \\
(0.002)\end{array}$ & $\begin{array}{l}0.010^{* * * *} \\
(0.004)\end{array}$ \\
\hline \multicolumn{7}{|l|}{ Panel 3: care adequacy 1} \\
\hline Inadequate care (by the & $0.019 * * *$ & $0.018 * * *$ & $0.016 * * *$ & $0.032 * * *$ & $0.020^{* * * *}$ & $0.012 * * *$ \\
\hline APNCU index) & $(0.002)$ & $(0.002)$ & $(0.002)$ & $(0.004)$ & $(0.002)$ & $(0.004)$ \\
\hline \multicolumn{7}{|l|}{ Panel 4: care adequacy 2} \\
\hline Inadequate care (by the & $0.013 * * *$ & $0.012 * * *$ & $0.011 * * *$ & $0.026 * * *$ & $0.014 * * *$ & $0.011 * * *$ \\
\hline Kessner index) & $(0.002)$ & $(0.002)$ & $(0.002)$ & $(0.004)$ & $(0.002)$ & $(0.004)$ \\
\hline Maternal and paternal controls & $\mathrm{Y}$ & $\mathrm{Y}$ & $\mathrm{Y}$ & $\mathrm{Y}$ & $\mathrm{Y}$ & $\mathrm{Y}$ \\
\hline Infant gender and birth order & $\mathrm{Y}$ & $\mathrm{Y}$ & $\mathrm{Y}$ & $\mathrm{Y}$ & $\mathrm{Y}$ & $\mathrm{Y}$ \\
\hline Infant birth weight & $\mathrm{N}$ & $\mathrm{Y}$ & $\mathrm{N}$ & $\mathrm{N}$ & $\mathrm{N}$ & $\mathrm{N}$ \\
\hline Mother fixed effects & Y & Y & Y & Y & Y & $\mathrm{Y}$ \\
\hline $\begin{array}{l}\text { Sample mean (no } \\
\text { breastfeeding) }\end{array}$ & 0.28 & 0.28 & 0.31 & 0.10 & 0.28 & 0.30 \\
\hline Number of mothers & 166,364 & 166,364 & 141,426 & 24,938 & 147,157 & 19,207 \\
\hline Number of sibling births & 351,935 & 351,935 & 301,234 & 50,701 & 294,314 & 57,621 \\
\hline
\end{tabular}

Columns 1-2 use the full sample of mothers, columns 3-4 stratify the sample by state, and columns 5-6 stratify the sample by number of births. The maternal control variables include mother's age, education, marital status, WIC enrollment, delivery payment types, pre-pregnancy BMI and smoking, and year and month of conception; the paternal control variables are father's age, race, ethnicity, and education. Robust standard errors clustered at the mother's level are reported in parentheses.

PA, Pennsylvania; WA, Washington; APNCU, Adequacy of Prenatal Care Utilization; BMI, body mass index.

*Significant at $10 \%$ level;

**significant at $5 \%$ level;

*** significant at $1 \%$ level.

Table A2 where maternal hypertension, county-level unemployment rates, and year by month effects all enter the regression model.

We also perform three additional sensitivity analyses, with the full results available upon request. First, because Table VII uses a selected group of the three-birth women, one may wonder how generalizable the results are. Data limitations prohibit a direct test on generalizability for postpartum body weight or smoking. However, we do find that the estimated effects of prenatal care on postpartum breastfeeding by the same selected group of three-birth women are very close to the results from all the two-birth or three-birth mothers (columns 5 and 6 in Table VI). This similarity lends credence to the thought that the results by this subsample in general may have good external validity. Second, findings by state are consistent with the baseline results, although the estimates for Washington (with a small sample size) are insignificant. Third, all the results in the even-numbered columns are robust, when we instrument for postnatal body weight, smoking, and newborn birth weight by the lagged values after taking the first difference of equation (2).

Table VIII summarizes the results when both the onset and frequency of care are simultaneously controlled in the regressions. Columns 1-5 examine the prenatal outcomes. Compared with the women with both timely and sufficient visits, the women having late care onset but a sufficient number of visits still have significantly higher risks of insufficient gestational weight gain, prenatal smoking, PROM, and precipitous labor. The point 
Table VII. Effects of prenatal care on postpartum body weight and smoking

\begin{tabular}{|c|c|c|c|c|c|c|}
\hline & \multicolumn{2}{|c|}{ Postnatal underweight } & \multicolumn{2}{|c|}{ Postnatal overweight or obese } & \multicolumn{2}{|c|}{ Postnatal smoking } \\
\hline & (1) & (2) & (3) & (4) & (5) & (6) \\
\hline \multicolumn{7}{|l|}{ Panel 1: care onset } \\
\hline Care onset in the second trimester & $\begin{array}{l}0.010^{* * * *} \\
(0.003)\end{array}$ & $\begin{array}{l}0.010 * * * \\
(0.003)\end{array}$ & $\begin{array}{c}0.002 \\
(0.004)\end{array}$ & $\begin{array}{c}0.002 \\
(0.004)\end{array}$ & $\begin{array}{l}0.008 * * \\
(0.004)\end{array}$ & $\begin{array}{l}0.008 * * \\
(0.004)\end{array}$ \\
\hline Care onset in the third trimester & $\begin{array}{l}0.012 * * * \\
(0.004)\end{array}$ & $\begin{array}{l}0.012 * * * \\
(0.004)\end{array}$ & $\begin{array}{c}-0.007 \\
(0.008)\end{array}$ & $\begin{array}{c}-0.007 \\
(0.008)\end{array}$ & $\begin{array}{l}0.020 * * * \\
(0.007)\end{array}$ & $\begin{array}{l}0.020 * * * \\
(0.007)\end{array}$ \\
\hline \multicolumn{7}{|l|}{ Panel 2: number of visits } \\
\hline Low frequency of care visits & $\begin{array}{l}0.013 * * * \\
(0.002)\end{array}$ & $\begin{array}{l}0.013 * * * \\
(0.002)\end{array}$ & $\begin{array}{c}0.004 \\
(0.004)\end{array}$ & $\begin{array}{c}0.004 \\
(0.004)\end{array}$ & $\begin{array}{l}0.008 * * \\
(0.003)\end{array}$ & $\begin{array}{l}0.008 * * \\
(0.003)\end{array}$ \\
\hline \multicolumn{7}{|l|}{ Panel 3: care adequacy 1} \\
\hline Inadequate care (by the APNCU index) & $\begin{array}{l}0.009 * * * \\
(0.002)\end{array}$ & $\begin{array}{l}0.009 * * * \\
(0.002)\end{array}$ & $\begin{array}{c}0.001 \\
(0.004)\end{array}$ & $\begin{array}{c}0.001 \\
(0.004)\end{array}$ & $\begin{array}{l}0.009 * * * \\
(0.003)\end{array}$ & $\begin{array}{l}0.009 * * * \\
(0.003)\end{array}$ \\
\hline \multicolumn{7}{|l|}{ Panel 4: care adequacy 2} \\
\hline Inadequate care (by the Kessner index) & $\begin{array}{l}0.009 * * * \\
(0.002)\end{array}$ & $\begin{array}{l}0.009 * * * \\
(0.002)\end{array}$ & $\begin{array}{c}0.001 \\
(0.004)\end{array}$ & $\begin{array}{c}0.001 \\
(0.004)\end{array}$ & $\begin{array}{l}0.013 * * * \\
(0.003)\end{array}$ & $\begin{array}{l}0.013 * * * \\
(0.003)\end{array}$ \\
\hline Maternal and paternal controls & $\mathrm{Y}$ & $\mathrm{Y}$ & $\mathrm{Y}$ & $\mathrm{Y}$ & $\mathrm{Y}$ & $\mathrm{Y}$ \\
\hline Infant gender and birth order & $\mathrm{Y}$ & $\mathrm{Y}$ & $\mathrm{Y}$ & $\mathrm{Y}$ & $\mathrm{Y}$ & $\mathrm{Y}$ \\
\hline Infant birth weight & $\mathrm{N}$ & $\mathrm{Y}$ & $\mathrm{N}$ & $\mathrm{Y}$ & $\mathrm{N}$ & $\mathrm{Y}$ \\
\hline Mother fixed effects & $\mathrm{Y}$ & Y & $\mathrm{Y}$ & $\mathrm{Y}$ & $\mathrm{Y}$ & $\mathrm{Y}$ \\
\hline $\begin{array}{l}\text { Sample mean (postpartum body weight } \\
\text { and smoking) }\end{array}$ & 0.04 & 0.04 & 0.45 & 0.45 & 0.21 & 0.21 \\
\hline Number of mothers & 19,207 & 19,207 & 19,207 & 19,207 & 19,207 & 19,207 \\
\hline Number of sibling births & 38,414 & 38,414 & 38,414 & 38,414 & 38,414 & 38,414 \\
\hline
\end{tabular}

All the regressions use the sample of the three-birth mothers and their first two births delivered in the sample period. The maternal control variables include mother's age, education, marital status, WIC enrollment, delivery payment types, pre-pregnancy BMI and smoking, and indicators of the year and month when the postnatal outcomes were measured; the paternal control variables are father's age, race, ethnicity, and education. Robust standard errors clustered at the mother's level are reported in parentheses.

APNCU, Adequacy of Prenatal Care Utilization; BMI, body mass index.

*Significant at $10 \%$ level;

**significant at $5 \%$ level;

$* * *$ significant at $1 \%$ level.

estimates on late care onset are slightly smaller than their counterparts in panels 1 and 2 of Table II. In addition, the magnitude of the estimates ranges from $3 \%$ to $23 \%$ (relative to the means of the outcome variables). Conditioning on early care onset, low frequency of care visits still moderately increases the probabilities of the aforementioned four adverse prenatal outcomes by 3-13\%. Similar patterns emerge for the postnatal measures. Columns 6 and 9 suggest that poor prenatal care utilization in only one dimension drives up the likelihoods of no breastfeeding and smoking by $2-10 \%$. By column 7 , the corresponding adverse effects on postnatal underweight are more sizable. Again, the association between prenatal care and excessive weight gain or high BMI postpartum is weak and insignificant (columns 2 and 8).

The last concern is that testing hypotheses on multiple outcomes can significantly increase the chance of detecting a significant effect on one of such outcomes, when we use the usual thresholds for statistical significance (e.g., 5\%) for each hypothesis testing. We follow the literature to adjust the $p$-values for the family of prenatal outcomes (multiply the original $p$-values by 5 ) and postnatal outcomes (multiply the original $p$-values by 4 ) by a very conservative Bonferroni correction (Savin, 1984). Contrasting the corrected $p$-values and the usual thresholds gives the adjusted statistical significance for each estimate. Table A3 in the Supporting Information shows that almost all the previously significant estimates in the benchmark analysis remain highly significant at $5 \%$ with the Bonferroni correction. Moreover, the findings are robust in other cases of testing multiple hypotheses, such as pooling all the outcomes (multiply the original $p$-values by 9) or considering multiple treatments regarding prenatal care (further multiply the corrected $p$-values in Table A3 by 5). 


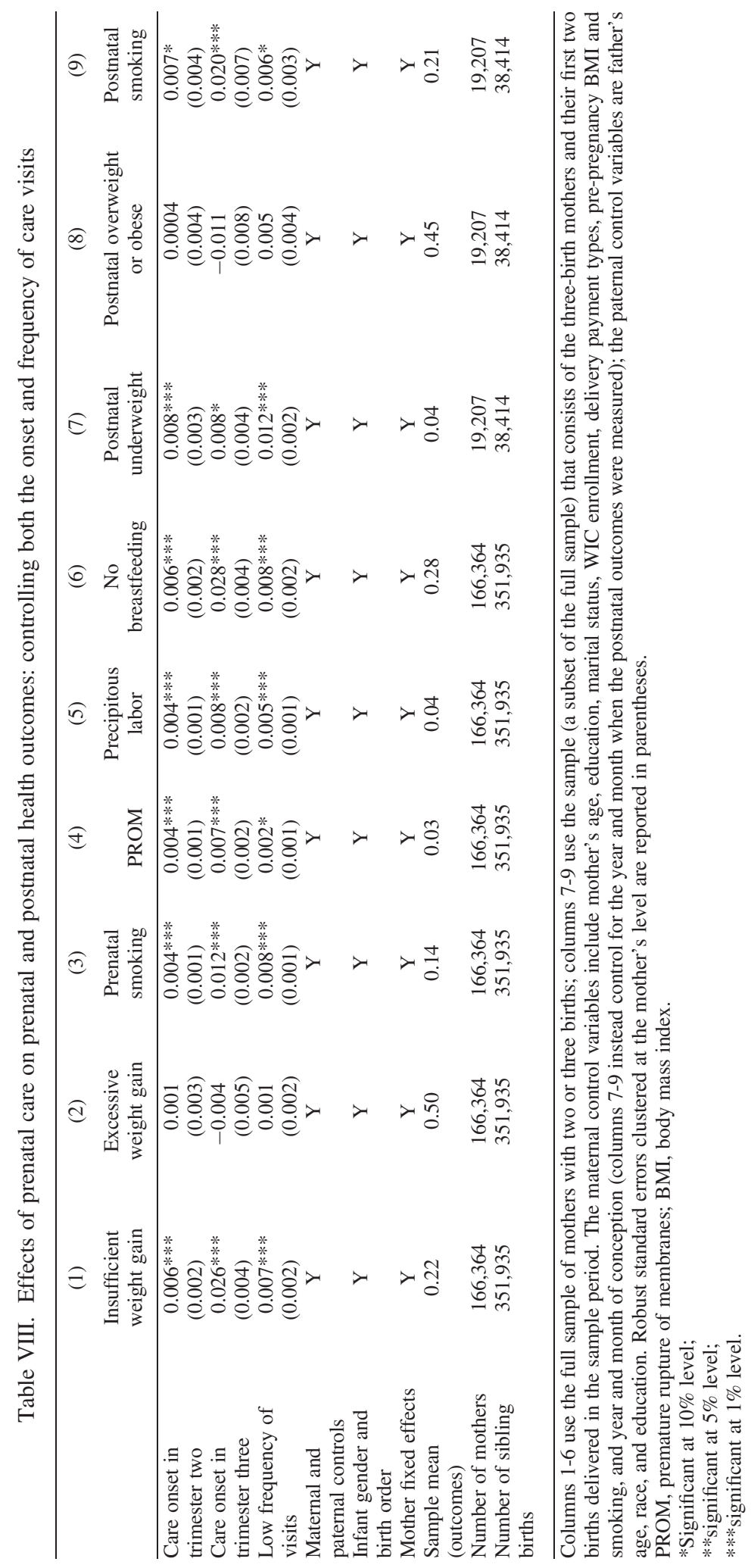




\section{CONCLUSION}

While many economic studies have explored the role of prenatal care in infant health production, there is little literature about the effects of prenatal care on maternal health. This research contributes to this understudied but important area using a rich and large data of sibling newborns delivered by 0.17 million mothers. We find, first, about $30 \%$ of the mothers initiated care beyond the first trimester, $62 \%$ had low frequency of care visits, and about 30$40 \%$ of them had inadequate care by the two care utilization indexes. Second, the baseline estimation with mother fixed effects shows that poor utilization of prenatal care because of late care onset or low frequency of visits significantly increases the risks of the following adverse maternal outcomes: insufficient gestational weight gain, prenatal smoking, PROM, precipitous labor, no breastfeeding, postnatal underweight, and postpartum smoking. The magnitude of the estimates (relative to the corresponding bases) is also meaningful, which varies from 3\% to $33 \%$.

The benchmark results are robust in a variety of sensitivity checks. In particular, poor prenatal care utilization in only one element (either late onset or low frequency of visits) still negatively affects maternal health and health behaviors to a nontrivial degree. Our new evidence therefore suggests that both early onset of care and having a sufficient number of care visits matter for improving maternal health. The empirical method used in this study can also be readily applied to investigate the other elements of prenatal care (e.g., quality), additional maternal pregnancy complications (with detection and treatment fully reported), and health outcomes of the mothers in other states. Furthermore, we acknowledge that the empirical model has not controlled for some important birth-varying variables such as maternal stress and income. As another limitation, this study focuses exclusively on the mothers having two or three births within 4-8 years, which only covers part of all the reproductive years of a woman.

The high prevalence of poor prenatal care utilization among mothers reported earlier is certainly an important public health concern. It will be interesting to explore the causes of such variation (both within and across markets) by subsequent research (Skinner, 2012). If the demand-side factors such as income and access are important in explaining underuse of prenatal care, then, further expanding insurance coverage can be an effective intervention. However, inadequate care utilization and the associated welfare loss may mainly come from incomplete information on maternal health production, which has led some physicians to underestimate the incremental benefits of better prenatal care to expectant mothers (Phelps, 2000). In this case, policies that increase diffusion of the true productivity of timely and sufficient care plus promote the latest practice guideline for prenatal care (Alexander and Kotelchuck, 2001; American College of Obstetricians and Gynecologists, 2012) among health professionals may significantly reduce the efficiency loss because of under-provision of prenatal care.

\section{ACKNOWLEDGEMENTS}

This research benefits from comments by Adam Atherly, Reagan Baughman, W. David Bradford, Jeremy Bray, Karen Smith Conway, Hope Corman, Partha Deb, Young Kyung Do, Erin Fletcher, Winnie Fung, Deniz Gevrek, Scotte Grosse, Aparna Lhila, Omar Robles, Virginia Wilcox-Gok, Ning Zhang, and other participants of American Society of Health Economist Conference, Association for Public Policy Analysis and Management Conference, Eastern Economic Association Meeting, and Southern Economic Association Meeting. Research grants are provided by the Center for New Institutional Social Science at Washington University in Saint Louis and ASU Walker College of Business Dean's Club.

\section{REFERENCES}

Abrevaya J, Dahl CM. 2008. The effects of birth inputs on birthweight: evidence from quantile estimation on panel data. Journal of Business \& Economic Statistics 26(4): 379-397.

Acharya S. 1995. How effective is antenatal care to promote maternal and neonatal health? International Journal of Gynecology \& Obstetrics 50: S35-S42. 
Alexander GR, Kotelchuck M. 1996. Quantifying the adequacy of prenatal care: a comparison of indices. Public Health Reports 111(5): 408-418.

Alexander GR, Kotelchuck M. 2001. Assessing the role and effectiveness of prenatal care: history, challenges, and directions for future research. Public Health Reports 116(4): 306-316.

Almond D, Mazumder B. 2013. Fetal origins and parental responses. Annual Review of Economics 5(1): 37-56.

American College of Obstetricians and Gynecologists. 2012. Committee on Obstetric Practice. In Guidelines for Perinatal Care (7th edn), Washington DC: American College of Obstetricians and Gynecologists.

Blumenthal D, Collins SR. 2014. Health care coverage under the Affordable Care Act - a progress report. New England Journal of Medicine 371(3): 275-281.

Boone JL. 1991. Stress and hypertension. Primary Care 18(3): 623-649.

Cameron AC, Trivedi PK. 2005. Part V: Models for Panel Data. Microeconometrics: Methods and Applications, Cambridge University Press: New York.

Cararach V, Botet F, Sentis J, Arimany MC. 1993. The maternal and perinatal complications of premature rupture of membranes. Contemporary Reviews in Obstetrics and Gynaecology 5: 85-89.

Carlson K. 2015. Fear itself: the effects of distressing economic news on birth outcomes. Journal of Health Economics 41: $117-132$.

Cawley J, Markowitz S, Tauras J. 2004. Lighting up and slimming down: the effects of body weight and cigarette prices on adolescent smoking initiation. Journal of Health Economics 23(2): 293-311.

Center for Chronic Disease Prevention and Health Promotion. 2001. Women and smoking: a report of the surgeon general. In Department of Health and Human Service, Office of the Surgeon General: Washington, DC.

Conway KS, Deb P. 2005. Is prenatal care really ineffective? Or, is the 'devil' in the distribution? Journal of Health Economics 24(3): 489-513.

Conway KS, Kutinova A. 2006. Maternal health: does prenatal care make a difference? Health Economics 15(5): 461-488.

Cunningham FG, Gant NF, Leveno KJ, Gilstrap LC, Hauth JC, Wenstrom KD. 2001. Williams Obstetrics (21 ${ }^{\text {st }}$ edn), McGraw-Hill Press: New York.

Currie J, Almond D. 2011. Human Capital Development before Age Five. Handbook of Labor Economics, 4, 1315-1486, The North-Holland Press: Amsterdam.

Currie J, Gruber J. 1996. Saving babies: the efficacy and cost of recent changes in the Medicaid eligibility of pregnant women. Journal of Political Economy 104(6): 1263-1296.

De la Torre L, Flick AA, Istwan N, Rhea D, Cordova Y, Dieguez C, Desch C, González-Quintero VH. 2011. The effect of new antepartum weight gain guidelines and prepregnancy body mass index on the development of pregnancy-related hypertension. American Journal of Perinatology 28(4): 285-292.

Dodds L, Fell DB, Joseph KS, Allen VM, Butler B. 2006. Outcomes of pregnancies complicated by Hyperemesis gravidarum. Obstetrics \& Gynecology 107(2, Part 1): 285-292.

Duff P. 1991. Premature rupture of membranes. Clinical Obstetrics and Gynecology 34(4): 683-684.

Epstein AM, Newhouse JP. 1998. Impact of Medicaid expansion on early prenatal care and health outcomes. Health Care Financing Review 19(4): 85-99.

Evans WN, Lien DS. 2005. The benefits of prenatal care: evidence from the PAT bus strike. Journal of Econometrics 125: 207-239.

Fertig AR, Watson T. 2009. Minimum drinking age laws and infant health outcomes. Journal of Health Economics 28(3): 737-747.

Ford ES, Moriarty DG, Zack MM, Mokdad AH, Chapman DP. 2001. Self-reported body mass index and health-related quality of life: findings from the behavioral risk factor surveillance system. Obesity Research 9(1): 21-31.

Furberg H, Newman B, Moorman P, Millikan R. 1999. Lactation and breast cancer risk. International Journal of Epidemiology 28(3): 396-402.

Gosselink CA, Ekwo EE, Woolson RF, Moawad A, Long CR. 1992. Dietary habits, prepregnancy weight, and weight gain during pregnancy: risk of preterm rupture of amniotic sac membranes. Acta Obstetricia et Gynecologica Scandinavica 71(6): 425-438.

Hedderson MM, Gunderson EP, Ferrara A. 2010. Gestational weight gain and risk of gestational diabetes mellitus. Obstetrics and Gynecology 115(3): 597-6040.

Hu FB. 2003. Overweight and obesity in women: health risks and consequences. Journal of Women's Health 12(2): $163-172$.

Institute of Medicine. 2009. Weight Gain during Pregnancy: Reexamining the Guidelines, National Academy Press: Washington, DC.

Ip S, Chung M, Raman G, Chew P, Magula N, DeVine D, Trikalinos T, Lau J. 2007. Breastfeeding and maternal and infant health outcomes in developed countries. In Evidence Report/Technology AssessmentNumber 153, Agency for Healthcare Research and Quality: Rockville, MD.

Kelly SJ, Lilley JM, Leonardi-Bee J. 2010. Associations of morbidity in the underweight. European Journal of Clinical Nutrition 64(5): 475-482. 
Kotelchuck M. 1994. An evaluation of the Kessner adequacy of prenatal care index and a proposed adequacy of prenatal care utilization index. American Journal of Public Health 84(9): 1414-1420.

Kutinova A, Conway KS. 2008. What about mom? The forgotten beneficiary of the Medicaid expansions. Southern Economic Journal 74(4): 1070-1104.

Labbok MH. 2001. Effects of breastfeeding on the mother. Pediatric Clinics of North America 48(1): $143-158$.

Luan NN, Wu QJ, Gong TT, Vogtmann E, Wang YL, Lin B. 2013. Breastfeeding and ovarian cancer risk: a meta-analysis of epidemiologic studies. The American Journal of Clinical Nutrition 98(4): 1020-1031.

Mahon TR, Chazotte C, Cohen WR. 1994. Short labor: characteristics and outcome. Obstetrics \& Gynecology 84(1): 47-51.

McAfee T, Burnette D. 2014. The impact of smoking on women's health. Journal of Women's Health 23(11): 881-885.

McDonagh M. 1996. Is antenatal care effective in reducing maternal morbidity and mortality? Health Policy and Planning 11(1): $1-15$.

Nizalova OY, Vyshnya M. 2010. Evaluation of the impact of the mother and infant health project in Ukraine. Health Economics 19(S1): 107-125.

Park S, Sappenfield WM, Bish C, Salihu H, Goodman D, Bensyl DM. 2011. Assessment of the Institute of Medicine recommendations for weight gain during pregnancy: Florida, 2004-2007. Maternal and Child Health Journal 15(3): 289-301.

Phelps C. 2000. Information diffusion and best practice adoption. In Handbook of Health Economics1, The North-Holland Press: Amsterdam; 223-264.

Poma PA. 1996. Premature rupture of membranes. Journal of the National Medical Association 88(1): $27-32$.

Reichman NE, Corman H, Noonan K, Dave D. 2009. Infant health production functions: what a difference the data make. Health Economics 18(7): 761-782.

Reichman NE, Corman H, Noonan K, Schwartz-Soicher O. 2010. Effects of prenatal care on maternal postpartum behaviors. Review of Economics of the Household 8(2): 171-197.

Roelands J, Jamison MG, Lyerly AD, James AH. 2009. Consequences of smoking during pregnancy on maternal health. Journal of Women's Health 18(6): 867-872.

Savin NE. 1984. Multiple hypothesis testing. In Handbook of Econometrics Vol. 2, Elsevier Science Publishers: Amsterdam; 827-879.

Seltzer V. 2000. Smoking and women's health. International Journal of Gynecology \& Obstetrics 70(1): 159-163.

Sheiner E, Levy A, Mazor M. 2004. Precipitate labor: higher rates of maternal complications. European Journal of Obstetrics \& Gynecology and Reproductive Biology 116(1): 43-47.

Skinner J. 2012. Causes and consequences of regional variations in health care. In Handbook of Health Economics 2 , The North-Holland Press: Amsterdam; 45-93.

Truong YN, Yee LM, Caughey AB, Cheng YW. 2015. Weight gain in pregnancy: does the Institute of Medicine have it right? American Journal of Obstetrics and Gynecology 212(3): 362-364.

US Department of Health and Human Services. 2012. Topic Area 26: Maternal, Infant, and Child Health. Healthy People 2020. US Department of Health and Human Services, Public Health Service: Washington DC.

US Department of Health and Human Services. 2015. The Affordable Care Act: Advancing the Health of Women and Children. Office of the Assistant Secretary for Planning and Evaluation, US Department of Health and Human Services: Washington DC.

Villar J, Merialdi M, Gülmezoglu AM, Abalos E, Carroli G, Kulier R, De Onis M. 2003. Nutritional interventions during pregnancy for the prevention or treatment of maternal morbidity and preterm delivery: an overview of randomized controlled trials. The Journal of Nutrition 133(5): 1606S-1625S.

Viswanathan M, Siega-Riz AM, Moos MK, Deierlein A, Mumford S, Knaack J, Thieda P, Lux LJ, Lohr KN. 2008. Outcomes of maternal weight gain, Agency for Healthcare Research and Quality: Rockville, MD.

Wooldridge JM. 2002. Econometric Analysis of Cross Section and Panel Data, MIT Press: Cambridge.

Yeo S, Crandell JL, Jones-Vessey K. 2016. Adequacy of prenatal care and gestational weight gain. Journal of Women's Health 25(2): 117-123.

\section{SUPPORTING INFORMATION}

Additional supporting information may be found in the online version of this article at the publisher's web site. 